\title{
Two-Envelope System for Consultant Selection using Weighted Sum Model
}

\author{
Mohd Faizal Bin Omar ${ }^{1 *}$, Bambang Trigunarsyah ${ }^{2}$, Johnny Wong $^{3}$ \\ ${ }^{1}$ School of Quantitative Sciences, College of Art \& Science, Universiti Utara Malaysia, Malaysia \\ ${ }^{2}$ School of Property, Construction and Project Management, RMIT University, Australia \\ ${ }^{3}$ School of Built Environment, Faculty of Design, Architecture and Building, University of Technology Sydney, Australia \\ *Corresponding author_E-mail: faizal_omar@uum.edu.my
}

\begin{abstract}
Consultant Selection is one of a classical problem in Multi Criteria Decision Making (MCDM). Most of the literature in Operation Research only concentrates on model building rather than developing an inclusive analytic tool that extends to a Decision Support System (DSS). In this paper, we deploy a case study approach to understand the user requirement for DSS development. We observe the process of consultant selection and the decision making at one of the technical department which involve in the infrastructure project in Malaysia. A two-envelope system and a simple Weighted Sum Model are currently in use. We demonstrate the abstraction and application based on two case projects. Sensitivity analysis is also performed and the result shows that the decision changed if it is solely based on fees or with minimal quality criteria. Finally, we gather the findings from the organizational flows, user modelling and decision making process in order to benchmark with our future works. This will helps us to better understand and develop an improved decision support model or tools for consultant selection problem.
\end{abstract}

Keywords: Decision support system, Multi criteria decision making, Requirement engineering, Weighted sum model

\section{Introduction}

The process of Requirement Elicitation (RE) for DSS is vital towards successful software development [1]. The application domain under consideration has to be characterized in terms of stakeholders' roles and of their objectives, and decision making processes involved in construction projects [2]. However, RE for MCDM problem are often overlooked particularly in construction project management discipline. This is because most of the literature in the area only focuses on model development rather than the analytics of DSS [3-5]. This paper demonstrates a case study for $\mathrm{RE}$ in consultant selection process at one of the technical department in Malaysia, namely Department A. We performed the twoenveloped system with Weighted Sum Model to observe and measure the impact of decision making. The result will be the benchmark for our future decision making model. Apart from that, other user requirements are also captured to be considered in our future prototype development.

\section{Requirement Elicitation for Decision Sup- port}

Elicitation of requirement can be regarded as an initial step where the name itself suggests to "capture" the needs of problem domain. It is at this point the process where the needs of the users and goals for the system are determined. Requirement elicitation can be broadly defined as the acquisition of goals, constraints, and features for a proposed system by means of investigation and analysis [6]. Information gathered from the elicitation process usually has to be interpreted, analysed, modelled, and validated before proceeding to the system development [7]. RE in DSS concerns on three main aspects i.e. organizational settings, user model and decision model (Figure 1)

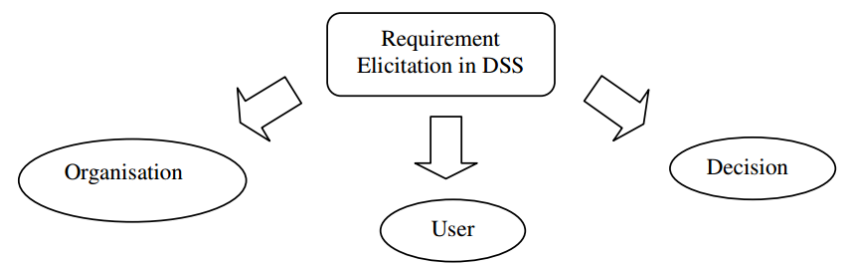

Fig 1: Elements of Requirement Elicitation in DSS [8].

In order to perform RE for our problem, we divide our activities into three dimension i.e. Organisation, User and Decision. We have gathered the flow of decision making in the organization [5]. In the next section, we carried out the development of user modelling to collect decision maker's opinion on their needs, expectation, experiences and necessary decision criteria for consultant selection. A semi structured interviews were conducted with five senior officers involved with decision making in the organisation for more than seven years. Three of the decision makers are head of departments and two are district engineers. In addition, quantity surveyor officer was also involved to verify the procedure and consultant selection process. To increase the validity of the data, documental analyses involving a number of government circulars were also performed. These approaches help to gain a clear understanding on the current practice of selection process.

Thereafter, the pattern of decision making style was examined in decision model section. Similarly, this phase involved the same decision makers where they were given tasks to complete technical assessment on two past projects using their current procedure. 


\section{Decision Making Process at the Technical Department}

In our research, we deploy case study to understand the problem, requirement and decision making scenario for consultant selection in Department A. Case study is a traditional approach to the study of topics in social science and management. It is an ideal methodology when a holistic, in depth investigation is needed [9]. In the area of Information System, a case study examines a phenomenon in its natural setting, employing multiple methods of data collection to gather information from one or a few entities such as people, groups, or organizations [10]. Thus, case study method is important to carry out system analysis and to investigate the design related to the process of consultant selection.

\subsection{Case Study Description}

In order to observe the decision making process, two case project were chosen, namely Case A and Case B where Case A is located in the border of Kedah-Penang state, and Case B to in Selangor state. Both cases are selected based on the following criteria, In order to produce meaningful result, this study has identified four main criteria as follows;

1. Project that has been completed. Project needs to be completed as it will provide some documentations or technical reports in the department.

2. The selection method is based on assessment. The selection method must provide some form of assessment i.e. technical and financial assessment. Direct negotiation is not suitable for this study.

3. The project hires local consultant. This is important because the availability of data on consultant's profile and standard set of criteria are practiced in the department for local consultants. This is to ease data analysis in the next stages and to provide some insights in the result.

4. The project is located in Malaysia. This is directed to the research problem where decision making problems were identified in Malaysia.

5. Project Type. Most of decision problems involving were directed to infrastructure project.

6. Size of Project. Project are also chosen between middle to top range size of project as indicates by Malaysian Ministry of Finance

7. Project Delivery. Project cases are chosen based on different type of project delivery

\subsection{User Modelling for Decision Support}

Generally, DSS can be considered as a custom made software to help specific decision maker. With the aim of designing DSS in mind, a usability model was adopted to assist in the design process. It is more focus on the individual preferences of the user. Specific user modelling attributes was elicited from the perspectives of decision makers. There are 7 attribute of user model suggested by [9] including (1) user needs and expectations, (2) existing knowledge and skills, (3) existing experience, (4) user goals and tasks, (5) physical attributes, (6) cultural and attitude information (7)[11]. These attributes were elicited from decision maker's point of view i.e. applicant and technical committee member. A sample of interview questions is presented in Appendix B2. The overall summary of usability modelling is shown in Table 1 . This summary is useful to be a communication medium of usability for designers in interface design.
Table 1: Summary of User Modelling for Decision Support

\begin{tabular}{|c|c|c|c|c|}
\hline \multirow{2}{*}{$\begin{array}{c}\text { User } \\
\text { Modelling } \\
\text { Attributes }\end{array}$} & \multirow[b]{2}{*}{ Key Evidence } & \multicolumn{3}{|c|}{ Decision Makers } \\
\hline & & DM1 & DM2 & DM3 \\
\hline \multirow{5}{*}{$\begin{array}{l}\text { User needs } \\
\text { and expecta- } \\
\text { tions }\end{array}$} & minimize processing time & $\checkmark$ & $\checkmark$ & $\checkmark$ \\
\hline & $\begin{array}{l}\text { easy and efficient tools to } \\
\text { complete task }\end{array}$ & & $\checkmark$ & $\checkmark$ \\
\hline & user friendly the system & $\checkmark$ & $\checkmark$ & \\
\hline & $\begin{array}{l}\text { reliable and transparent of the } \\
\text { system }\end{array}$ & $\checkmark$ & & $\checkmark$ \\
\hline & support group decision & $\checkmark$ & & \\
\hline \multirow[t]{2}{*}{$\begin{array}{l}\text { User goals } \\
\text { and current } \\
\text { tasks }\end{array}$} & $\begin{array}{l}\text { Technical and financial as- } \\
\text { sessment by technical commit- } \\
\text { tee }\end{array}$ & $\checkmark$ & $\checkmark$ & $\checkmark$ \\
\hline & $\begin{array}{l}\text { technical assessment by appli- } \\
\text { cant during prequalification }\end{array}$ & & & \\
\hline \multirow{5}{*}{$\begin{array}{l}\text { Existing } \\
\text { Knowledge } \\
\text { and skills }\end{array}$} & Manual technical assessment & $\checkmark$ & $\checkmark$ & $\checkmark$ \\
\hline & Usage of web based system & $\checkmark$ & $\checkmark$ & $\checkmark$ \\
\hline & Usage of desktop based system & $\checkmark$ & $\checkmark$ & $\checkmark$ \\
\hline & Usage of DSS & & & \\
\hline & Manual consultant searching & & & \\
\hline \multirow{2}{*}{$\begin{array}{l}\text { Cultural } \\
\text { factors }\end{array}$} & no fancy icon & $\checkmark$ & & \\
\hline & $\begin{array}{l}\text { Malay or English Language } \\
\text { preferred }\end{array}$ & $\checkmark$ & & \\
\hline \multirow{6}{*}{$\begin{array}{l}\text { Existing } \\
\text { experience }\end{array}$} & Manual system: Easy to use & $\checkmark$ & & \\
\hline & $\begin{array}{l}\text { Manual system: Easy to use } \\
\text { but lengthy process }\end{array}$ & & & \\
\hline & $\begin{array}{l}\text { Occasional error in current } \\
\text { system }\end{array}$ & & $\checkmark$ & $\checkmark$ \\
\hline & $\begin{array}{l}\text { Political influence might effect } \\
\text { the transparency of the system }\end{array}$ & & & \\
\hline & Conflict during assessment & $\checkmark$ & & \\
\hline & $\begin{array}{l}\text { Some information might not be } \\
\text { accessible during assessment }\end{array}$ & $\checkmark$ & & \\
\hline \multirow{2}{*}{$\begin{array}{l}\text { Physical } \\
\text { attributes }\end{array}$} & Professional display layout & & & \\
\hline & Match with department layout & $\checkmark$ & & \\
\hline \multirow{3}{*}{$\begin{array}{l}\text { Attitude } \\
\text { Information }\end{array}$} & Easy to learn system & & $\checkmark$ & \\
\hline & Simple system is anticipated & $\checkmark$ & & $\checkmark$ \\
\hline & Noticeable function & $\checkmark$ & & \\
\hline
\end{tabular}

\subsection{Decision Making Process: Two-Envelope System}

The process of decision making at Department $A$ has been described in [4]. Basically it is based on two-envelope system if it is not a direct negotiation project. According to [9], two-envelop system are define as bidding activities are to be submitted in two parts: the "Cost" part which contains the offer with respect to the award criteria, i.e. in most cases only the price; while the "Quality" part contains all other documentation and information related to the bid. The "Quality" part is opened first and only after evaluation of whether the selection criteria have been met can the "Cost" part of all submitted bids be opened and evaluated [12]. Generally, this process should ensure that the price does not influence the technical evaluation of the bid [12].

\subsection{Criteria and Alternatives for Consultant Selection}

Based on the interview and document analysis, there are four standard criteria that is currently practiced in the department for technical assessment i.e. organisational staffing, general experience, experience in same project/studies and current workload. In addition, there is also a criterion for consultant fee that will be combined with technical assessment in the final decision making. Table 2 describes the criteria for consultant selection.

Table 2: Description of Criteria for Consultant Selection

\begin{tabular}{|c|c|c|}
\hline Variable & Criterion & Description \\
\hline CR1 & $\begin{array}{c}\text { Organisation } \\
\text { and staffing }\end{array}$ & $\begin{array}{c}\text { Organisation is considered as a whole } \\
\text { where it encompasses the number of pro- } \\
\text { fessional compare to project size and key } \\
\text { personnel staff }\end{array}$ \\
\hline CR2 & $\begin{array}{c}\text { General } \\
\text { Experience }\end{array}$ & $\begin{array}{c}\text { Level of experience with infrastructure } \\
\text { project/studies and competency in manag- } \\
\text { ing projects in general }\end{array}$ \\
\hline
\end{tabular}




\begin{tabular}{|c|c|c|}
\hline CR3 & $\begin{array}{c}\text { Experience in } \\
\text { the same } \\
\text { project/studies }\end{array}$ & $\begin{array}{c}\text { Specific experience with similar pro- } \\
\text { ject/studies that has been completed (or } \\
\text { ongoing) }\end{array}$ \\
\hline CR4 & Workload & $\begin{array}{c}\text { Ongoing infrastructure project/studies or } \\
\text { current workload/task }\end{array}$ \\
\hline fees & $\begin{array}{c}\text { Consultant } \\
\text { fees }\end{array}$ & $\begin{array}{c}\text { Total fees proposed by the consultant's } \\
\text { candidate }\end{array}$ \\
\hline
\end{tabular}

During the interviews, a total of 8 consultants were taken into consideration in the case projects. In Case A, 3 consultants were selected and Case B considered 5 candidates. Table 3 describes the alternatives in relation with Case A and Case B.

Table 3: Potential Consultants and its variables

\begin{tabular}{|c|c|c|}
\hline Alternatives & Case A & Case B \\
\hline $\mathrm{A}_{1}$ & Consultant 1 & Consultant 4 \\
\hline $\mathrm{A}_{2}$ & Consultant 2 & Consultant 5 \\
\hline $\mathrm{A}_{3}$ & Consultant 3 & Consultant 6 \\
\hline $\mathrm{A}_{4}$ & Consultant 7 \\
\hline $\mathrm{A}_{5}$ & & Consultant 8 \\
\hline
\end{tabular}

\subsection{Decision Hierarchy}

A decision model is developed based on hierarchical structure of decision making defined by [10] (Figure 2). The top level is the objective followed by criteria level and alternatives level [13].

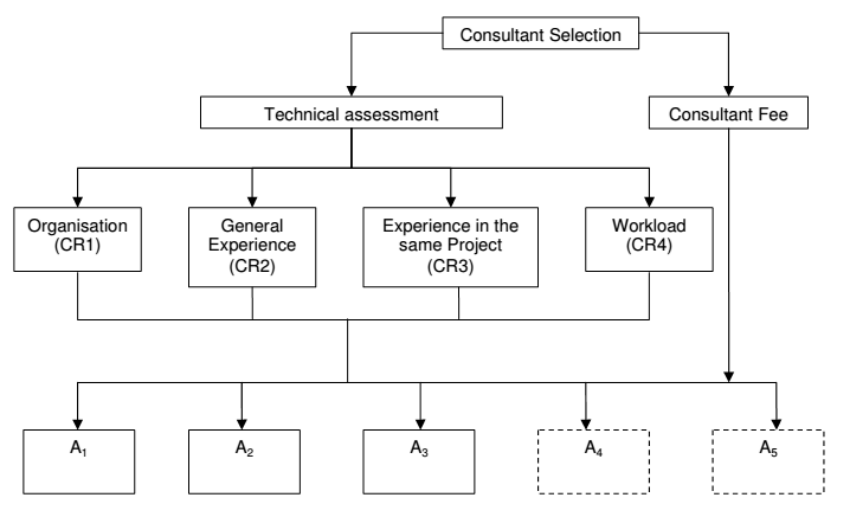

Fig. 2: Hierarchical Decision Structure for Consultant Selection at $D e$ partment $A$

\subsection{Multi Criteria Decision Making}

Figure 2 illustrates the basic structure of MCDM. MCDM problem involves the selection of the 'best' alternative from a pool of pre-selected alternatives described in terms of their criteria [14-16]. As shown in [14-16], many researchers in construction area have developed various decision models to solve construction related MCDM problems. Models such as AHP, ANP and TOPSIS were among the prominent approaches that have been applied $[3,4]$. These models help analysts to arrive at the best decision and provide clear rational for choices made. In our case, we deploy Weighted Sum Model as it one of the simple and easy to understand approach.

\section{Application of Weighted Sum Model in the Pre-Qualification Process}

The pre-qualification process are conducted by the technical committee which consist of three decision makers i.e. Decision Maker 1, DM1, Decision Maker 2, DM2 and Decision Maker 3, DM3. They are required to complete the technical assessment form. Given the marking scheme in the assessment form, one can easily formulate the scoring function. Each criterion is associated with weight of $\mathrm{w}_{\mathrm{j}}$. Total Score, TS for each $\mathrm{A}_{\mathrm{i}}$ is as follows;

$\mathrm{TS}=\sum_{j=1}^{n} w_{j} a_{i j}$

All decision makers are the expert and possess the vast experience in the department. Table 4, Table 5, Table 6 and Table 7 present the results drawn from the assessment by the decision makers. The maximum scoring function, TS is 100 and the weight allocations are as follows: $w_{1}=30, w_{2}=40, w_{3}=20, w_{4}=10$

Table 4: Assessment by DM1 (value in percentage)

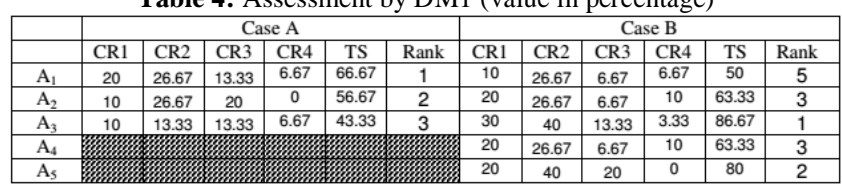

Table 5: Assessment by DM2 (value in percentage)

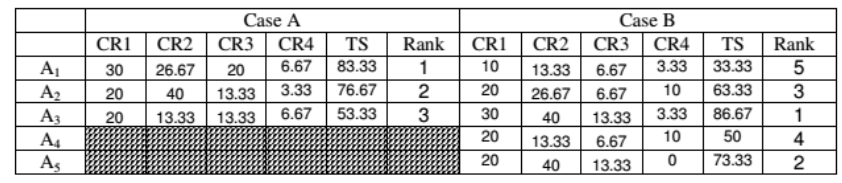

Table 6: Assessment by DM3 (value in percentage)

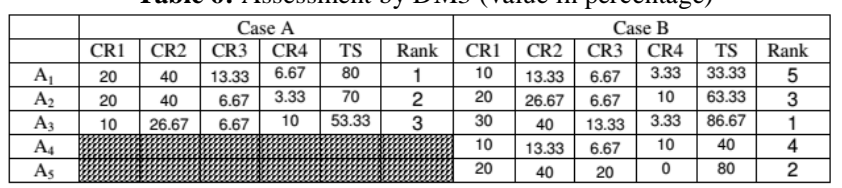

Table 7: Aggregation of Technical Assessment by decision makers (value in percentage)

\begin{tabular}{|c|c|c|c|c|c|c|c|c|c|c|}
\hline & \multicolumn{5}{|c|}{ Case A } & \multicolumn{5}{|c|}{ Case B } \\
\hline & DM1 & DM2 & DM3 & $\overline{T S}$ & Rank & DM1 & DM2 & DM3 & $T S$ & Rank \\
\hline$A_{1}$ & 66.67 & 83.33 & 80 & 76.67 & 1 & 50 & 33.33 & 33.33 & 38.89 & 5 \\
\hline $\mathrm{A}_{2}$ & 56.67 & 76.67 & 70 & 67.78 & 2 & 63.33 & 63.33 & 63.33 & 63.33 & 3 \\
\hline$\overline{A_{3}}$ & 43.33 & 53.33 & 53.33 & 50 & 3 & 86.67 & 86.67 & 86.67 & 86.67 & 1 \\
\hline $\mathrm{A}_{4}$ & & & & & & 63.33 & 50 & 40 & 51.11 & 4 \\
\hline $\mathrm{A}_{5}$ & & & & & & 80 & 73.33 & 80 & 77.78 & 2 \\
\hline
\end{tabular}

The selection method is based on two-envelope system. Hence, the costing element prepared by consultant candidate will be combined with technical committee's assessment to yield the final score, $F S_{i}$. The standard proportion of weighting between technical assessment, $w^{\text {tech }}$ and fee, $w^{\text {fees }}$ is 80:20. The fee is calculated as inversely proportional to the minimum price. From the procedure, $F S_{i}$ can be defined as follows;

$F S_{i}=\left(w^{\text {tech }} \frac{\overline{T S}}{100}\right)+w^{\text {fees }}\left(\frac{\min _{i} \text { fees }_{i}}{\text { fees }_{i}}(100)\right)$

Table 8 summarises the final decision making upon combination of the fees for both cases.

Table 8: Final Decision Making

\begin{tabular}{|c|c|c|c|c|c|c|c|c|}
\hline & \multicolumn{5}{|c|}{ Case A } & \multicolumn{4}{c|}{ Case B } \\
\hline & $\overline{T S}$ & fees & $F S$ & Rank & $\overline{T S}$ & fees & $F S$ & Rank \\
\hline $\mathrm{A}_{1}$ & 76.67 & 97.04 & 80.74 & 1 & 38.89 & 97.24 & 50.59 & 5 \\
\hline $\mathrm{A}_{2}$ & 67.78 & 98.32 & 73.89 & 2 & 63.33 & 100 & 70.67 & 3 \\
\hline $\mathrm{A}_{3}$ & 50 & 100 & 60 & 3 & 86.67 & 93.76 & 88.09 & 1 \\
\hline $\mathrm{A}_{4}$ & & & & & 51.11 & 99.20 & 60.73 & 4 \\
\hline $\mathrm{A}_{5}$ & & & & & 77.78 & 92.92 & 80.81 & 2 \\
\hline
\end{tabular}


The final decision indicates that Consultant 1 and Consultant 6 rank the highest for Case A and Case B respectively.

In addition, we also performed Sensitivity Analysis to observe the impact of decision making if we gradually change the weight allocation for $\overline{T S}$ and fees.

\subsection{Sensitivity Analysis for Case A}

Table 9 and Figure 3 show the weight changes and the effect of consultant's performances. The decision change dramatically where A3 will be selected if selection process only consider fee or with minimal $T S$ value / "quality" criteria

Table 9: Weight changes in Case A

\begin{tabular}{|r|rr|r|r|r|}
\hline \multicolumn{2}{|c|}{ Weight Change } & \multicolumn{3}{|c|}{ Alternatives } \\
\hline \multicolumn{1}{|c|}{ Technical } & \multicolumn{1}{|c|}{ Fee } & \multicolumn{1}{|c|}{ A1 } & A2 & \multicolumn{1}{|c|}{ A3 } \\
\hline 1 & 0 & 76.67 & 67.78 & 50 \\
\hline 0.9 & 0.1 & 78.707 & 70.834 & 55 \\
\hline 0.8 & 0.2 & 80.744 & 73.888 & 60 \\
\hline 0.7 & 0.3 & 82.781 & 76.942 & 65 \\
\hline 0.6 & 0.4 & 84.818 & 79.996 & 70 \\
\hline 0.5 & 0.5 & 86.855 & 83.05 & 75 \\
\hline 0.4 & 0.6 & 88.892 & 86.104 & 80 \\
\hline 0.3 & 0.7 & 90.929 & 89.158 & 85 \\
\hline 0.2 & 0.8 & 92.966 & 92.212 & 90 \\
\hline 0.1 & 0.9 & 95.003 & 95.266 & 95 \\
\hline 0 & 1 & 97.04 & 98.32 & 100 \\
\hline
\end{tabular}

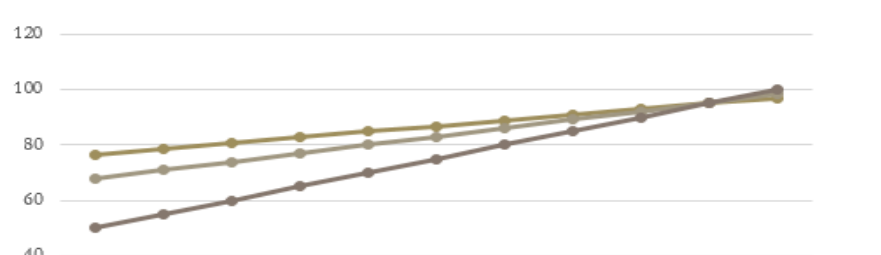

20

Techns

Price

Fig. 3: Performance of Consultants in different condition for Case A

\subsection{Sensitivity Analysis for Case B}

In Case B, similar condition occurs with Case A where alternatives A2 outperformed the other candidates.

Table 10: Weight changes in Case B

\begin{tabular}{|r|r|r|r|r|r|r|}
\hline \multicolumn{1}{|c|}{ Weight Change } & \multicolumn{6}{|c|}{ Alternatives } \\
\hline Technical & \multicolumn{1}{|c|}{ Fee } & \multicolumn{1}{|c|}{$\mathbf{A 1}$} & \multicolumn{1}{|c|}{$\mathbf{A 2}$} & \multicolumn{1}{|c|}{$\mathbf{A 3}$} & \multicolumn{1}{c|}{$\mathbf{A 4}$} & \multicolumn{1}{c|}{$\mathbf{A 5}$} \\
\hline 1 & 0 & 38.89 & 63.33 & 86.67 & 51.11 & 77.78 \\
\hline 0.9 & 0.1 & 44.725 & 66.997 & 87.379 & 55.919 & 79.294 \\
\hline 0.8 & 0.2 & 50.56 & 70.664 & 88.088 & 60.728 & 80.808 \\
\hline 0.7 & 0.3 & 56.395 & 74.331 & 88.797 & 65.537 & 82.322 \\
\hline 0.6 & 0.4 & 62.23 & 77.998 & 89.506 & 70.346 & 83.836 \\
\hline 0.5 & 0.5 & 68.065 & 81.665 & 90.215 & 75.155 & 85.35 \\
\hline 0.4 & 0.6 & 73.9 & 85.332 & 90.924 & 79.964 & 86.864 \\
\hline 0.3 & 0.7 & 79.735 & 88.999 & 91.633 & 84.773 & 88.378 \\
\hline 0.2 & 0.8 & 85.57 & 92.666 & 92.342 & 89.582 & 89.892 \\
\hline 0.1 & 0.9 & 91.405 & 96.333 & 93.051 & 94.391 & 91.406 \\
\hline 0 & 1 & 97.24 & 100 & 93.76 & 99.2 & 92.92 \\
\hline
\end{tabular}

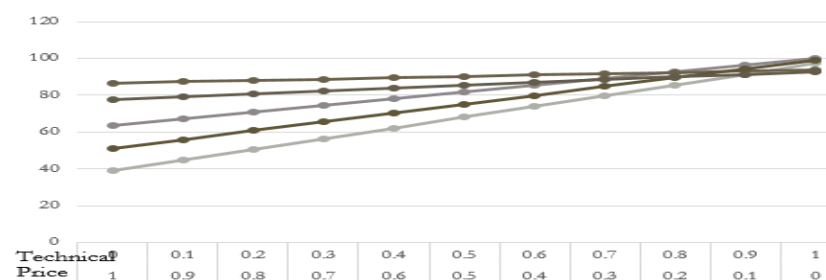

Fig. 4: Performance of Consultants in different condition for Case B

\section{Discussion and Conclusion}

We demonstrated our approach for requirement gathering before we performed further analysis in order to develop a DSS. It is a mixed research approach where case study has been used to understand the phenomena of decision making within an organisation. Weighted Sum Model is a useful tool and easy to understand. This technique can be described as a weighted linear combination or scoring method [17]. It is also a representation of the DM's preferences in a linear additive function [17].

The contributions of this paper are twofold. First, we introduce the element of RE in developing MCDM model including the user modeling. RE process needs to be organised in a proper documentation such as by worksheet methodology $[2,18]$. Second, we use WSM to observe decision making process and identify the effect for consultant selection

In our next phase, we will document the requirements into worksheet for future requirement analysis.

\section{Acknowledgement}

This research is supported by Ministry of Education Malaysia and Universiti Utara Malaysia. We thank our colleagues from Queensland University of Technology who provided insight and expertise that greatly assisted the research.

\section{References}

[1] Cheng BHC \& Atlee JM (2007), "Research Directions in Requirements Engineering," presented at the Future of Software Engineering (FOSE '07).

[2] Tsui F \& Karam O (2007), Essentials of software engineering. Sudbury, Mass. :: Jones and Bartlett Publishers.

[3] Omar MF, Trigunarsyah B \& Wong J (2008), "Decision making tools for infrastructure project planning," presented at the 2nd International Conference on Built Environment in Developing Countries, Penang, Malaysia.

[4] Omar MF, Trigunarsyah B \& Wong J, "Infrastructure project planning decision making : challenges for decision support system applications," presented at the Proceedings of the 7th Asia Pacific Structural Engineering and Construction Conference \& 2nd European Asian Civil Engineering Forum, Awana Porto Malai, Langkawi, (2009).

[5] Omar MF, Trigunarsyah B \& Wong J, "Decision support system architecture for consultant selection," presented at the Proceedings of the International Symposium on Construction in Developing Economies: Commonalities Among Diversities, Penang, Malaysia, (2009).

[6] Coulin C \& Zowghi D, "Requirements Elicitation for Complex Systems: Theory and Practice," in Requirements Engineering For Sociotechnical Systems, J. L. Mate and A. Silva, Eds., ed Hershey, PA: Information Science Publishing, (2005).

[7] Finkelstein A, "Requirements engineering: a review and research agenda," in Software Engineering Conference, 1994. Proceedings., 1994 First Asia-Pacific, (1994), pp. 10-19.

[8] Giorgini P, Rizzi S, \& Garzetti M (2008), "GRAnD: A goaloriented approach to requirement analysis in data warehouses," Decision Support Systems, vol. 45, pp. 4-21.

[9] Feagin J, A. Orum A \& Sjoberg G (1991), A case for case study. Chapel Hill, NC: University of North Carolina Press.

[10] Benbasat I, Goldstein D \& Mead M (1987), "The Case Research Strategy in Studies of Information Systems," MIS Quarterly, vol. 11, pp. 369-386.

[11] Adikari S (2008), "Usability Modelling For Requirements Engineering," Degree of Master of Engineering, Faculty of Information Sciences and Engineering, University of Canberra, ACT.

[12] Organisation for Economic Cooperation and Development (2016, 22nd of June 2018). Country case: Two-envelope system used in the bids submission phase in the Slovak Republic Available: https://www.oecd.org/governance/procurement/toolbox/search/twoenvelope-system-bid-submission-phase-slovak-republic.pdf 
[13] Saaty TL (1994), "How to make a decision: The analytic hierarchy process," Interfaces, vol. 24, pp. 19-43.

[14] Lu J, Zhang G, Ruan D \& Wu F (2007), Multi-objective Group Decision Making: Methods Software And Applications With Fuzzy Set Techniques vol. 6. London, UK: Imperial Colleage Press.

[15] Nursal AT, Omar MF \& Nawi MNM, "An overview of emerging technologies in contemporary decision support system development," in AIP Conference Proceedings, (2014), pp. 634-638.

[16] Nursal AT, Omar MF \& Nawi MNM (2018), "The Application of Fuzzy TOPSIS to the selection of Building Information Modeling Software," Journal of Telecommunication, Electronic and Computer Engineering (JTEC), vol. 10, pp. 1-5.

[17] Esangbedo MO \& Che A (2016), "Grey Weighted Sum Model for Evaluating Business Environment in West Africa," Mathematical Problems in Engineering, vol. 2016, p. 14.

[18] Lau D \& Mylopoulos J (2004), "Designing Web Services with Tropos. ," in IEEE International Conference on Web Services 2004. 